\title{
Comparative Study of Learning Style, Resiliency and Problem Solving Skills in Iranian Chess Players
}

\author{
Abbas Sadeghi' ${ }^{1}$, Seyed Hamed Mousavian² \\ ${ }^{1}$ Department of Educational Sciences, University of Guilan, Rasht, Iran \\ ${ }^{2}$ Department of Clinical Psychology, University of Islamic Azad University, Rasht, Iran \\ Email: asadeghi1394@gmail.com
}

How to cite this paper: Sadeghi, A., \& Mousavian, S. H. (2018). Comparative Study of Learning Style, Resiliency and Problem Solving Skills in Iranian Chess Players. Advances in Physical Education, 8, 58-65. https://doi.org/10.4236/ape.2018.81007

Received: January 17, 2018

Accepted: February 10, 2018

Published: February 13, 2018

Copyright (c) 2018 by authors and Scientific Research Publishing Inc. This work is licensed under the Creative Commons Attribution International License (CC BY 4.0).

http://creativecommons.org/licenses/by/4.0/ (c) (i) Open Access

\begin{abstract}
The main objective of this study was to compare learning styles, resiliency and problem solving skills in Iranian chess players. The approach of this study was a description of cohesion kind. The statistical population included all active chess players with an international rating under chess federation supervision of Islamic Republic of Iran. The sample was based on Morgan table, and the sampling was done by simple method and the number of 306 players was chosen who answered the learning style questionnaire of Clop in 2005, Kaner \& Davidson's Resiliency in 2003, and Kasidi \& Long's problem solving guideline in 1996. The data obtained by Chi-square Test, Kolmogorov-Smirnov Test (KS test), Kruskal-Wallis Test \& Spearman correlation Test analyzed by SPSS21. The findings showed that there wasn't a significant relationship between learning styles with the amount of resiliency and chess players' problem solving skills. Also there was a positive and powerful relation between the amount of resiliency and chess players solving problem skills. It seems that chess players learning style doesn't have any effect on the ability of problem-solving skill. In other word, having learning style and different thinking isn't an advantage although the present research protects the existence of positive meaningful relation between the amount of resiliency and chess players' problem solving skills.
\end{abstract}

\section{Keywords}

Learning Styles, Resiliency, Solving Problem Skills, Chess Players

\section{Introduction}

One of the determinant psychological elements to achieve success in sport is 
learning style. Learning styles mention the ways that people create concept, rules and theory so that they could be guided in new situations. Woolfolk defines the learning styles as different ways for receiving and organizing of information. According to this definition, learning style refers to differences among individuals in preferring perception ways, organizing and analysing information and experiences in learning new concepts.

According to Hansen (2005) Jean-Marie Hiltorp, the professor of human resources, divided learning styles into four groups which are:

1) Reflectors: Their decisions are based on focusing on general concept and observation (alternate choices).

2) Activists: Their decisions are based on fact and observation (test and error).

3) Theorists: Their decisions are based on focusing on general concept and logic (model for everything).

4) Operatives: Their decisions are based on reality and logic (the thing that should be done).

One of the theoretical models in study of the ways to overcome sport stress is positive psychology approach. The main duty of this approach is to survey and recognition of abilities, weak points, talents and individual goodness. Tolerance is one of these concepts and normal structures with regard to positive psychology.

Masten (2001) believes that tolerance is called "dynamic process of positive adaptation to unpleasant experiences" and Tedeschi et al. (1998) calls it "stress resistance" or "post-traumatic growth". Ingram \& Price (2001) emphasizes that, it is along with an annex by different degree of resistance situated against psychological damages. Bouna (2004) implies that tolerance is based on this definition and is beyond being safe from stress and harshness of life and Richardson (2002) says that it is adjusted to positive growth, adaptation and reaching to a level of equality after making a disorder in former equality situation. Therefore, tolerance refers to a successful adaptation that appears in disastrous and unpleasant stress. This definition of tolerance shows a dynamic structure that needs a complicated interaction between dangerous and protective factors (Olson et al., 2003; Luthar et al., 2000).

In fact, tolerance mentions that one despite of being under extensive pressure and dangerous factors can improve his or her social power and overcome problems and become successful. Issacson (2002) pointed out that the result of Isakson's shows that tolerable students are able to protect their self-usefulness, evaluate their circumstances, reinforce commitment to their goals and increase the motivated behavior and finally acquire high achievement. Martin \& Marsh (2006) also through surveying high school student proved that the amount of tolerance has an important role in decrease or increase of students' educational motivation.

Tolerance is a kind of protection against social psychological difficulties and improves positive function of life. As Mohamadi (2005) writes, Werner \& Smit in 1992, claim that tolerance can be boosted by promoting life and social skills. 
Solving problem ability is one of these skills.

Wu et al. (1996) emphasize that solving problem is vital skill for today's life. Nowadays in all of activities, responsible people have been called to have high thinking and solving problem skills, both in public and technology area, rather in normal or problematic activities and in most societies everyone believes problem solving skill should improve in present time as a vital skill for life. Problem solving needs special and purposive approaches that one defines the problem through them, decide to find a solution executes the way of problem solving and observe it (Elliot et al., 1999).

Treffinger et al. (2008) define the problem solving style, stable individual differences in preferred method that people apply when facing difficulties. Cassidy \& Long (1996) also define problem solving style as a cognitive-behavioral process that through them people recognize effective ways to overcome problematic situations.

Jeffrey (2002) shows that teaching life skills increases individual power of adaptation for better solving of obstacles and positional problems. Therefore, weak challenging approaches and inappropriate ways for solving problems forecast dangerous behaviors (Ball 2004, 2005).

Totally some of personal characteristic like positive self-concept, being sociable, intelligence, adequacy in teaching, autonomy, self-esteem good relations, solving problem skills and psychological and physical health are the effective elements to increase tolerance in individual (Bonanno, 2004; Campbell-Sills et al., 2006; Gu \& Day, 2007; Veselska et al., 2009).

It seems that chess as a scientific, artistic and athletic field prepares a situation which one can examine different strategies and test their accuracy or inaccuracy.

Karimianpour (2010) pointed out that although the experts reach to guiding principles through experience and logic, but beginners involve themselves in various strategies and may be at the beginning of the trial and error method to achieve the basic strategy and in future opportunities play more active. Besharat (2010) results that according to the huge extent of problem solving application in all dimensions of human life, teaching chess can be used as a way to confront and involve with strategy and finding solutions to train problem solving skills and generalizing them in new opportunities. The present research in fact is going to answer this basic problem whether there is a meaningful relation between learning style, tolerance and problem solving skill or not.

\section{Methodology}

The present study was correlation type. The population consisted of all active chess players with international rating under chess federation supervision of the Islamic Republic of Iran for 1500 individual. Sample sizes due to possible non-cooperation of chess players with the number of 306 were selected randomly based on Morgan. To estimate learning styles in chess players, Kolb's learning styles questionnaire (2005) was used. To determine the validity, the content va- 
lidity method and to assess reliability test-retest interval of ten days run on a number of agreed subjects' coefficient was calculated that the score 0.80 obtained for this index. Also to determine the amount of tolerance, the Connor-Davidson's tolerance Scale in 2003 was used, which reliability and validity of its Persian form also in preliminary studies of normal samples and patients was confirmed and surveyed (Cronbach's Alpha Index 0.86). Finally, in order to measure problem-solving skills in chess players, Cassidy \& Lang strategies questionnaire in 1996 was used. The reliability of this test in a study by Saber (2011) through test-pretest (after one week) has been reported at 0.89. Also Babapour et al. in 2003 reported reliability of the scale by internal consistency (Cronbach's Alpha) equal to 0.77 . In order to examine the relationship between research variables Chi-square Test, Kolmogorov-Smirnov Test (KS test), Kruskal-Wallis Test \& Spearman correlation Test were used.

\section{Findings}

Table 1 and Table 2 show the results of Kruskal-Wallis' nonparametric test and its indexes in surveying the learning style and tolerance of chess players. Based on the result of Kruskal-Wallis test there wasn't meaningful relation between learning style and the amount of tolerance. In other word the amount of tolerance among chess players was approximately equal with different learning styles.

Table 3 and Table 4 show the results of Kruskal-Wallis' nonparametric test and its indexes in surveying the learning style and solving problem skills of chess players. Based on the result of Kruskal-Wallis test there wasn't meaningful relation between learning style and the solving problem skills. In other word the amount of solving problem skills among chess players was approximately equal to different learning styles.

Table 5 shows the result of Spearman test in surveying the tolerance and solving problem skills. Based on the result of Spearman's correlation test there was a powerful relation between tolerance and chess players solving problem

Table 1. Kruskal-Wallis' nonparametric test in surveying the learning style and tolerance.

\begin{tabular}{lc}
\hline & The average of ranks \\
\hline Pragmatic & 158.56 \\
Reflective & 140.76 \\
Theorist & 144.95 \\
Activist & 173.54 \\
\hline
\end{tabular}

Table 2. Kruskal-Wallis' test and its indexes in surveying the learning style and tolerance.

\begin{tabular}{cc}
\hline & Tolerance \\
\hline Chi-square & 3.57 \\
Degrees of freedom & 3 \\
Level of Significance & 0.311 \\
\hline
\end{tabular}


Table 3. Kruskal-Wallis' nonparametric test in surveying the learning style and problem solving.

\begin{tabular}{lc}
\hline & The average of ranks \\
\hline Pragmatic & 161.72 \\
Reflective & 141.67 \\
Theorist & 138.31 \\
Activist & 177.29 \\
\hline
\end{tabular}

Table 4. Kruskal-Wallis' test and its indexes in surveying the learning style and problem solving.

\begin{tabular}{cc}
\hline & problem solving \\
\hline Chi-square & 5.13 \\
Degrees of freedom & 3 \\
Level of Significance & 0.162 \\
\hline
\end{tabular}

Table 5. The result of Spearman's test in surveying the tolerance and solving problem.

\begin{tabular}{lcc}
\hline & \multicolumn{2}{c}{ Problem solving } \\
\hline \multirow{3}{*}{ Tolerance } & Correlation Coefficient & 0.879 \\
& Level of Significance & 0.000 \\
& Number & 303 \\
\hline
\end{tabular}

skills. In other word through increasing the amount of chess players' tolerance, the amount of solving problem skills will be extraordinary increased.

\section{Conclusions and Discussion}

The overall objective of this study was to compare the styles of learning, tolerance and problem-solving skills in chess players of Iran. According to research findings and based on the Kruskal-Wallis test results, there was no significant relationship between learning styles and the chess players' tolerance. In other words, the amount of tolerance was almost identical between the chess players with different learning styles. The result was not consistent with the findings of some similar studies. For example, Momeni in a research "Relationship between cognitive styles and learning styles of students with math anxiety" reached to the conclusion that between learning styles and independent cognitive style background with math anxiety, there is a significant correlation and also learning styles and independent cognitive style have the power to predict math anxiety. Momeni et al. (2015) believe the population and different measurement tools may be the reasons for these differences.

Also based on the Kruskal-Wallis test result between learning styles and problem-solving skills of chess players, there was no significant relationship, in other words, and the problem-solving skills among chess players with different learn- 
ing styles were almost identical. The obtained result also was inconsistent with many of previous findings that showed a meaningful relation between learning style and educational achievement, and also learning styles dependent on background and independent of background can play a significant role in the progress of testes, although their statistical population did not include chess players. To explain this result, it must be said that chess players with different learning styles can boost their ability by learning problem-solving skills in this area so that many chess players with different learning styles could become the world champion and probably learning style is not the decisive factor in capability to solve the problem.

Finally, Spearman's correlation coefficient result showed that there was a strong and positive relationship between the amount of chess players' tolerance and their problem-solving skills. It means that by increasing tolerance, it is expected that the amount of chess players' problem-solving skills significantly increases. The obtained result was consistent with other findings of Coşkun et al. (2014). To justify the above result, it should be mentioned that problem-solving skills require the individual's ability to influence their behavior rather than a mechanical reaction to the environment. Those who internalize leaning criteria for their own progress and set goals for themselves can change environmental factors on their behavior and arrange it and try more psychological tolerance and finally show high ability to solve problems.

In summary, it seems about chess players at least, learning style doesn't play an important role in case of tolerance and problem-solving skills although more research in this area is needed. This study supports the positive relationship between tolerance and problem-solving skill.

\section{References}

Ball, S. A. (2004). Personality Traits, Disorders, and Substance Abuse. In R. M. Stelmack (Eds.), On the Psychobiology of Personality: Essays in Honor of Marvin Zuckerman (pp. 203-222). New York: Pergamum. https://doi.org/10.1016/B978-008044209-9/50013-0

Ball, S. A. (2005). Personality Traits, Problems, and Disorders: Clinical Applications to substance Use Disorders. Journal of Research in Personality, 39, 84-102. https://doi.org/10.1016/j.jrp.2004.09.008

Besharat, M. A. (2010). Psychometrics Features of Persian Form for Tolerance Scale. Research Report, Tehran: Tehran University.

Bonanno, G. A. (2004). Loss, Trauma, and Human Resilience. American Psychologist, 59, 20-28. https://doi.org/10.1037/0003-066X.59.1.20

Bouna, G. W. (2004). The Individual and His Religion: A Psychological Interpretation. New York: Macmillan.

Campbell-Sills, L., Cohan, S. L., \& Stein, M. B. (2006). Relationship of Resilience to Personality, Coping, and Psychiatric Symptoms in Young Adults. Behavior Research and Therapy, 44, 585-599. https://doi.org/10.1016/j.brat.2005.05.001

Cassidy, T., \& Long, C. (1996). Problem Solving Style. Stress and Psychological Illness: 
Development of a Multi Factorial Measure. British Journal of Clinical Psychology, 3, 265-277. https://doi.org/10.1111/j.2044-8260.1996.tb01181.x

Coşkun, D., Garipağaoğlu, Ç., \& Tosun, Ü. (2014). Analysis of the Relationship between the Resiliency Level and Problem Solving Skills of University Students. Procedia - Social and Behavioral Sciences, 114, 673-680.

https://doi.org/10.1016/j.sbspro.2013.12.766

Elliot, T. R., Shewchuk, R. M., \& Richard, J. S. (1999). Care Giver Social Problem Solving Abilities and Family Member Adjustment to Recent-Onset Physical Disability. Rehabilitation Psychology, 44, 104-123. https://doi.org/10.1037/0090-5550.44.1.104

Gu, Q., \& Day, C. (2007). Teacher's Resilience: A Necessary Condition for Effectiveness. Teaching and Teacher Education, 23, 1302-1316.

https://doi.org/10.1016/j.tate.2006.06.006

Hansen, L. B. (2005). Foundations of Chess Strategy Paperback (pp. 32-33).

Ingram, R. E., \& Price, J. M. (2001). The Role of Vulnerability in Understanding Psychopathology. In R. E. Ingram, \& J. M. Price (Eds.), Vulnerability to Psychopathology: Risk across the Lifespan (pp. 3-19). New York, NY: The Guilford Press.

Issacson, B. (2002). Characteristics and Enhancement of Resiliency in Young People. A Research Paper for Master of Science Degree with Major in Guidance and Counseling, Menomonie, WI: University of Wisconsin-Stout.

Jeffrey, P. (2002). Competency Coping and Contributory Life Skills. Journal of Agricultural Education Pennsylvania University, 68-74.

Karimianpour, G. (2010). Survey the Effect of Teaching Chess on Children (between 5-7 Years) Solving Problem Skill, Tehran City 88-89 Year. MA Thesis for Preschool Training and Growth, Tehran: AllamehTabatabaie University.

Luthar, S. S., Cicchetti, D., \& Becker, B. (2000). The Construct of Resilience: A Critical Evaluation and Guidelines for Future Work. Child Development, 71, 543-562. https://doi.org/10.1111/1467-8624.00164

Martin, A. J., \& Marsh, H. W. (2006). Academic Resilience and Its Psychological and Educational Correlates: A Construct Validity Approach. Psychology in the Schools, 43, 267-281. https://doi.org/10.1002/pits.20149

Masten, A. (2001). Ordinary Magic: Resilience Processes in Development. American Psychologist, 56, 227-238. https://doi.org/10.1037/0003-066X.56.3.227

Mohamadi, M. (2005). Survey the Effective Factors on Tolerance of Individuals Issued by Drug Abuse. PHD Thesis, Toronto: University of Rehabilitation Science.

Momeni, K., Yazdanbakhsh, K., \& Faramarzi, F. (2015). The Relation of Cognitive Styles and Learning Style with Math Anxiety in Students (pp. 26-40).

Olson, C. A., Bond, L., Burns, J. M., Vella-Brodrick, D. A., \& Sawyer, S. M. (2003). Adolescent Resilience: A Conceptual Analysis. Journal of Adolescent, 26, 1-11. https://doi.org/10.1016/S0140-1971(02)00118-5

Richardson, C. (2002). Emotional Intelligence: A Meta-Anility Investigation of Predictive Validity and Homological Net. Journal of Vocational Behavior, 65, 71-95.

Tedeschi, R. G., Park, C. L., \& Calhoun, L. F. (1998). Posttraumatic Growth: Positive Changes.

Treffinger, D. J., Selby, E. C., \& Scott, G. I. (2008). Understanding Individual Problem-Solving Style: A Key to Learning and Applying Creative Problem-Solving. Learning and Individual Differences, 18, 390-401.

https://doi.org/10.1016/j.lindif.2007.11.007 
Veselska, Z., Geckova, A. M., Orosova, O., Gajdosova, B., Dijk, G. P., \&. Reijneveld, S. A. (2009). Self-Esteem and Resilience: The Connection with Risky Behavior among Adolescents. Addictive Behaviors, 34, 287-291.

https://doi.org/10.1016/j.addbeh.2008.11.005

Wu, T. F., Custer, R. L., \& Dyrenfurth, M. J. (1996). Technological and Personal Problem-Solving Styles: Is There a Difference? Journal of Technology Education, 7, 55-71. 